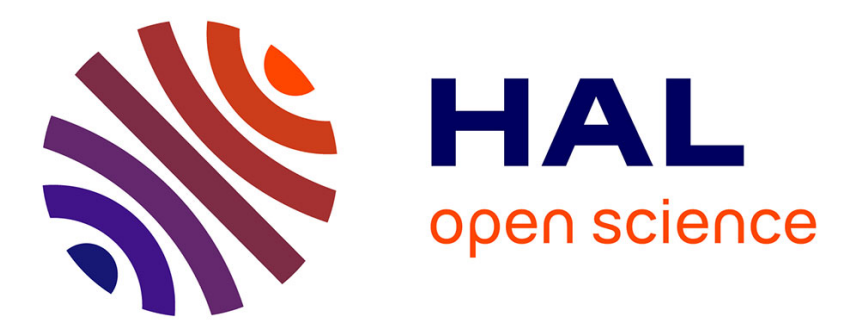

\title{
Cu-Ag core-shell nanoparticles: A direct correlation between micro-Raman and electron microscopy
}

M Cazayous, Cyril Langlois, T. Oikawa, Christian Ricolleau, A A Sacuto

\section{To cite this version:}

M Cazayous, Cyril Langlois, T. Oikawa, Christian Ricolleau, A A Sacuto. Cu-Ag core-shell nanoparticles: A direct correlation between micro-Raman and electron microscopy. Physical Review B: Condensed Matter and Materials Physics (1998-2015), 2006, 73 (11), 10.1103/PhysRevB.73.113402 . hal02161416

\section{HAL Id: hal-02161416 https://hal.science/hal-02161416}

Submitted on 20 Jun 2019

HAL is a multi-disciplinary open access archive for the deposit and dissemination of scientific research documents, whether they are published or not. The documents may come from teaching and research institutions in France or abroad, or from public or private research centers.
L'archive ouverte pluridisciplinaire HAL, est destinée au dépôt et à la diffusion de documents scientifiques de niveau recherche, publiés ou non, émanant des établissements d'enseignement et de recherche français ou étrangers, des laboratoires publics ou privés. 


\title{
Cu-Ag core-shell nanoparticles: A direct correlation between micro-Raman and electron microscopy
}

\author{
M. Cazayous, ${ }^{1,2, *}$ C. Langlois, ${ }^{1,2}$ T. Oikawa, ${ }^{1,3}$ C. Ricolleau, ${ }^{1,2}$ and A. Sacuto ${ }^{1,2}$ \\ ${ }^{1}$ Laboratoire Matériaux et Phénoménes Quantiques (UMR 7162), Université Denis-Diderot (Paris 7), 2 place Jussieu, \\ 75251 Paris, France \\ ${ }^{2}$ Laboratoire de Physique des Solides (UPR5 CNRS), Ecole Superieure de Physique et de Chimie Industrielle, 10 rue Vauquelin, \\ 75231 Paris, France \\ ${ }^{3}$ Application and Research Center, JEOL Ltd., 3-1-2 Musashino, Akishima, Tokyo 196-8558, Japan \\ (Received 5 December 2005; revised manuscript received 17 January 2006; published 15 March 2006)
}

\begin{abstract}
Vibration modes of metal core-shell nanoparticles have been measured by confocal micro-Raman spectroscopy. Compared to a standard macroscopic scale, the number of analyzed nanoparticles is reduced to $10^{3}-10^{4}$. We observed two distinct contributions in the same Raman spectrum originating from $\mathrm{Cu}-\mathrm{Ag}$ core-shell and pure Ag nanoparticles. The nanoparticle sizes are calculated and successfully compared to the ones obtained by electron microscopy on the same micron-scale area. The bond matching between $\mathrm{Cu}$ core and $\mathrm{Ag}$ shell is pointed out from a conjugated Raman and transmission electron microscopy study.
\end{abstract}

DOI: 10.1103/PhysRevB.73.113402

PACS number(s): 78.30.Fs, 81.07.Ta, 68.35.Iv

Core-shell nanoparticles have attracted much attention over the past decade due to their unique electronic properties, and their potential use in a wide panel of applications ranging from optical switches to biological labels. The surface-enhanced Raman scattering (SERS) takes advantage of the electron confinement in metallic nanoparticles for resonantly coupling the incident light to the plasmons and generate intense localized fields. ${ }^{1,2}$ In particular, the interaction with a plasmon induces a strong Raman scattering by acoustic phonons. ${ }^{3}$ The electron-phonon coupling and the properties of phonons in nanoparticles play an important role in the full understanding of SERS. The reliable interpretation of Raman spectra requires a complete characterization of nanoparticles at the finest scale. It is well known that the density of states of acoustic vibrations in isolated nanoparticles is discrete and that the low frequency Raman scattering is a powerful and suitable tool for studying their vibration modes. ${ }^{4-6}$ In the case of a spherical nanoparticle, normal vibrations can be divided into torsional and spheroidal modes. Torsional modes are purely transversal and have no radial displacement. Spheroidal modes have a mixed character of radial and tangential motions. Among these vibrations, a purely radial mode is known as a breathing mode. The quadrupolar vibrations corresponding to spheroidal vibrations with two deformation axes are usually observed whereas radial modes appear only in systems with narrow size distributions. ${ }^{7}$ Moreover, it has been shown recently that self-organized silver nanoparticles linked to organic chains can also establish coherent vibrations. ${ }^{8,9}$ To predict the local responses and to be able to discriminate among different theoretical and numerical approaches, the knowledge of the local nanoparticle structure and its environment has to be associated with the vibration modes. However, until now, Raman scattering from confined acoustic phonons has been limited to a macroscopic scale. The reduction of the Raman probed area allows us to directly compare the structural data deduced from the quadrupolar mode to the ones obtained from transmission electron microscopy (TEM) images on the identical area.
This paper presents a micro-Raman study of $\mathrm{Cu}-\mathrm{Ag}$ coreshell nanoparticles elaborated on a carbon thin film evaporated on a TEM microscopy grid. The confined vibration modes related to $\mathrm{Cu}-\mathrm{Ag}$ core-shell and pure $\mathrm{Ag}$ nanoparticles have been identified in the same spectrum. Several TEM techniques and analysis methods have been used to characterize the same area probed by micro-Raman measurements. The nanoparticle sizes, forms, and compositions deduced from the vibrational Raman and the electron microscopy are in good agreement. Two components in the Raman spectra, depending on the acoustic mismatch between $\mathrm{Cu}$ core and Ag shell, have been discerned and correlated to their respective crystallographic orientations.

Nanoparticles are prepared by thermal evaporation under ultrahigh vacuum. The substrate is heated at $400{ }^{\circ} \mathrm{C}$. After deposition, the nanoparticles are annealed for $.5 \mathrm{~h}$ at the same temperature. The evaporation rates for $\mathrm{Cu}$ and $\mathrm{Ag}$ were approximately $0.25 \mathrm{~nm} / \mathrm{min}$. Sample $A$ contains $\mathrm{Cu}$ nanoparticles obtained by a $2 \mathrm{~nm} \mathrm{Cu}$ deposition on a thin amorphous carbon film and supported by a microscopy grid with micronumerated square holes. This sample was then covered by a $1.5 \mathrm{~nm}$ aluminum layer in order to avoid oxidation of the $\mathrm{Cu}$ particles. Sample $B$ has been elaborated with the same $\mathrm{Cu}$ deposition as sample $A$ followed by $1 \mathrm{~nm}$ of $\mathrm{Ag}$ without additional aluminum film.

The structural characterizations of samples $A$ and $B$ were performed using several TEM techniques: high resolution imaging (HRTEM), energy filtered imaging (EFTEM), and scanning high angle dark field imaging (HAADF-STEM) (for details see Refs. 10 and 11). The microscope used for this study was a JEM-2100F field-emission TEM operated at $200 \mathrm{keV}$. The Raman scattering spectra were recorded at room temperature using a triple spectrometer Jobin Yvon T64000 with the high rejection rate in order to measure the low frequency Raman signal closed to the Rayleigh scattering. We used several excitation lines from a $\mathrm{Ar}^{+}-\mathrm{Kr}^{+}$mixed gas laser. The laser beam was guided into a microscope and focused through a $50 \times$ long working distance objective with a numerical aperture of 0.4 . The scattered light was collected 

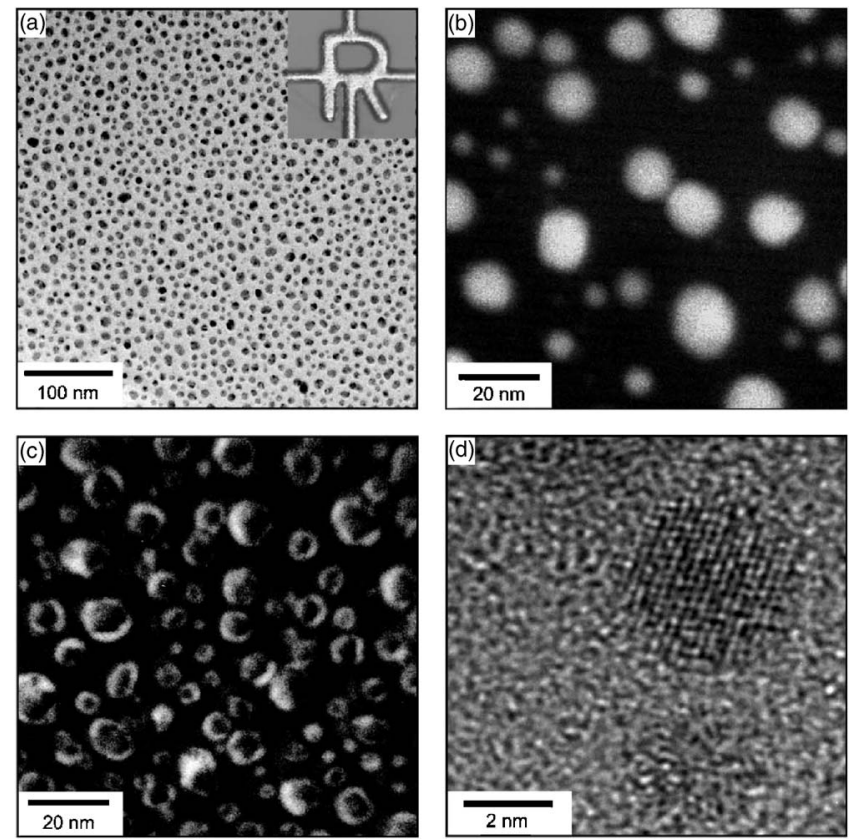

FIG. 1. Images of $\mathrm{Cu}-\mathrm{Ag}$ core-shell nanoparticles (sample $B$ ) obtained by (a) bright field TEM, (b) HAADF microscopy (the enhanced contrast compared to conventional TEM allows an efficient particle recognition and to distinguish two size distributions), (c) EFTEM showing the core-shell structure of the nanoparticles, and (d) HRTEM pointing out the lattice fringes corresponding to a pure Ag nanoparticle.

by the same objective. Samples were kept in vacuum in order to avoid Raman lines arising from air molecules at low frequencies and tilted at $40^{\circ}$ from the incident light direction to reject its reflection out of the objective. The initial spot diameter is about $1.5 \mu \mathrm{m}$ and was reduced to $0.7 \mu \mathrm{m}$ by the confocal setup. A better spot size cannot be achieved due to the tilt angle of the samples. The number of particles analyzed under the Raman spot is of the order of $10^{3}-10^{4}$ as deduced from the nanoparticle density of $10^{4} \mu \mathrm{m}^{-2}$ measured by TEM. This value has to be compared to macroscopic values closed to $10^{8}$ contained within a standard spot diameter of $100 \mu \mathrm{m}$. The Raman and TEM measurements have been performed on the same area. The area of interest was the channel formed by the letter $R$ of the numeration items and the rods of the microscopy grid [see inset in Fig. 1(a)]. Therefore Raman spectra are directly correlated to the exact nanoparticle distribution obtained by TEM on the same area.

Figure 2 shows Stokes and anti-Stokes Raman spectra recorded at low frequencies around the Rayleigh scattering (centered at $0 \mathrm{~cm}^{-1}$ ) on sample $A$ in the $R$ channel. Since no changes have been observed for sample $A$ along the channel, only one spectrum is presented for each wavelength. The observed Raman peak is associated with quadrupolar mode of the nanoparticle. ${ }^{4-6}$ This peak has been shown to come from a modulation of surface polarization charges via a deformation potential mechanism. The modulation is due to a modification of the nanoparticle surface orientation during the nanoparticle oscillation. ${ }^{12,13}$ A complete description of the Raman peak, in particular the intensity ratios between the

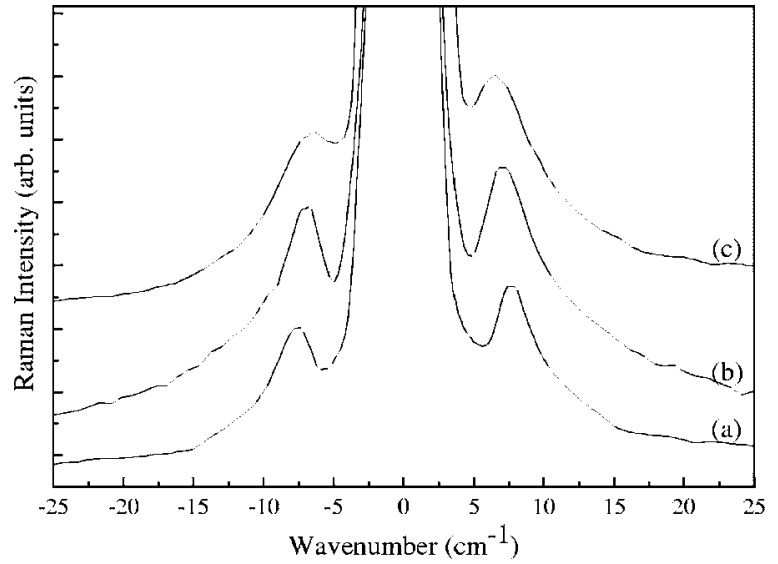

FIG. 2. Low frequency Raman spectra of $\mathrm{Cu}$ nanoparticles (sample A) excited at (a) $2.7 \mathrm{eV}$, (b) $2.41 \mathrm{eV}$, (c) $1.65 \mathrm{eV}$.

different torsional and spheroidal modes, needs to take into account the various coupling mechanisms between the surface plasmon-polaritons and the confined vibrations. Here, we limit our interest to the vibrational properties classically described by Lamb theory. ${ }^{14}$ For an elastic sphere of a diameter $D$ with a free surface, the vibration frequencies $\omega$ can be written in the following simplified form:

$$
\omega=\frac{\tau v_{t}}{D}
$$

where $\tau$ is the smallest positive root of an eigenvalue equation depending on the vibration mode considered (torsional or spheroidal) and on the ratio between longitudinal $v_{l}$ and transversal $v_{t}$ sound velocities. ${ }^{15}$

The diameter $D$ is calculated from Eq. (1) using the frequency at the maximum intensity of the low frequency peak recorded at $2.7 \mathrm{eV}$ on $\mathrm{Cu}$ nanoparticles. At this energy, nanoparticles with more spherical shape are selected (see below). As can be seen in Table I, the Raman calculated diameter is in agreement with the one measured by TEM using conventional image analysis. In Fig. 2 the Stokes peak shifts from $7.2 \mathrm{~cm}^{-1}$ to $6.5 \mathrm{~cm}^{-1}$ when the energy decreased from $2.7 \mathrm{eV}$ to $1.65 \mathrm{eV}$. To interpret the frequency shift of the quadrupolar mode with the incident wavelength, the morphology of the nanoparticle has to be taken into account. When the excitation is shifted to red it has already been shown that the observed nanoparticles tend to an ellipsoidal shape due to the tuning of the plasmon resonance. ${ }^{6}$ Our TEM measurements show the ellipsoidal shape of the $\mathrm{Cu}$ nanoparticles with a mean minor and major axis diameter of 8.3 and

TABLE I. Nanoparticle sizes (nm) measured by $\mu$-Raman and TEM on $\mathrm{Cu}, \mathrm{Cu}-\mathrm{Ag}$ and $\mathrm{Ag}$ nanoparticles. Ag shell thickness and pure Ag nanoparticle size have been obtained from EFTEM and HAADF images, respectively.

\begin{tabular}{cccc}
\hline \hline & $\mathrm{Cu}$ & $\mathrm{Ag}$ shell & $\mathrm{Ag}$ \\
\hline$\mu$-Raman & 9 & 1.6 & 4.6 \\
TEM & 9.6 & 1.8 & 5.4 \\
\hline \hline
\end{tabular}




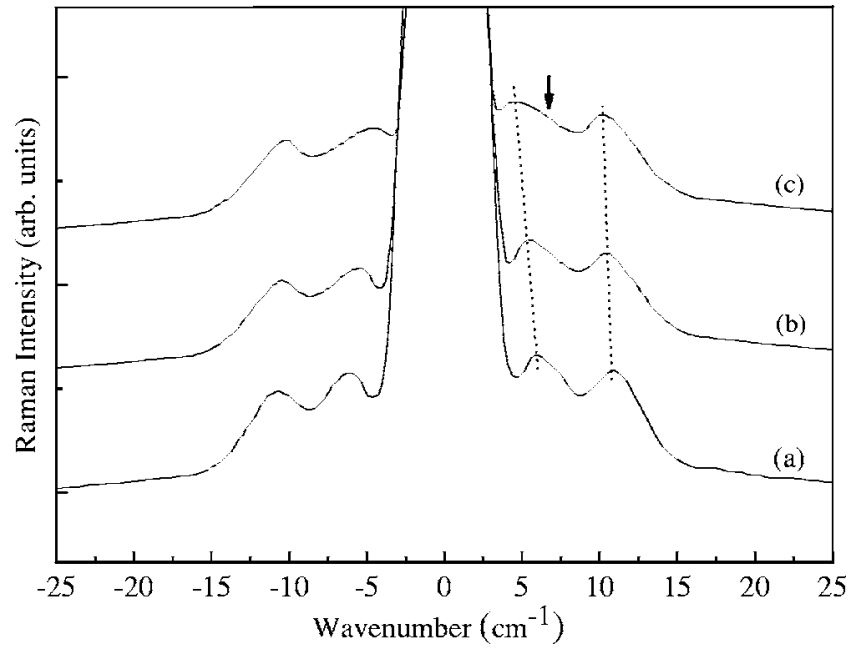

FIG. 3. Low frequency Raman spectra on $\mathrm{Cu}-\mathrm{Ag}$ core-shell nanoparticles (sample $B$ ) recorded at (a) $2.7 \mathrm{eV}$, (b) $2.41 \mathrm{eV}$, (c) $1.65 \mathrm{eV}$. Dashed lines are guides for the eyes.

$11.5 \mathrm{~nm}$, respectively. In the approximation of a sphere shape, the diameters deduced from Raman spectra are 9, 9.7, and $10.5 \mathrm{~nm}$ for $2.7,2.41$, and $1.65 \mathrm{eV}$ excitation energies, respectively. The mean nanoparticle diameter measured with the three excitation lines corresponds closely to the value of the mean major axis obtained by TEM. This selection based on the shape of the nanoparticles allowed us to reduce the number of nanoparticles probed. For the nanoparticles with a mean diameter of $9 \mathrm{~nm}$ selected at $2.7 \mathrm{eV}$, the number of observed nanoparticles can be estimated at $40 \%$ of the total distribution determined by TEM under the laser spot.

Figure 3 displays Raman spectra of $\mathrm{Cu}-\mathrm{Ag}$ core-shell nanoparticles at different energies. In contrast to those of Fig. 2, the spectra of Fig. 3 present two low frequency peaks despite only one associated with the quadrupolar mode of $\mathrm{Cu}-\mathrm{Ag}$ core-shell nanoparticles is expected. The lower frequency peak shifts towards the Rayleigh line, from $5.8 \mathrm{~cm}^{-1}$ to $4.9 \mathrm{~cm}^{-1}$, with the decreasing excitation energy. This behavior is the same as the one witnessed in $\mathrm{Cu}$ particles. The frequency of the upper peak is quite constant with a variation of only $0.4 \mathrm{~cm}^{-1}$ between the extreme wavelengths. This additional peak may be attributed to the particles' radial modes, or yet another unidentified nanoparticle specie. The latter is suspected because the observed two peaks are close in intensity whereas the radial mode's peak intensity is generally found to be weaker than that of quadrupolar modes. ${ }^{7,12}$ Moreover, radial modes are only observed with a narrow size distribution of particles. ${ }^{7}$ To determine the origin of the peak, TEM images have been performed using EFTEM and HRTEM techniques. The EFTEM image of Fig. 1(c) shows the $\mathrm{Cu}-\mathrm{Ag}$ core shell structure of the nanoparticles. The contrast is obtained by the image reconstruction exclusively with the electrons that have lost characteristic energy by inelastic interactions with silver. One extra nanoparticle specie is also visible: small white dots which may be interpreted as pure Ag nanoparticles or core-shell nanostructures beyond the spatial resolution of EFTEM images. HRTEM analysis has been done on these small particles [Fig. 1(d)]. The crystallographic analysis of
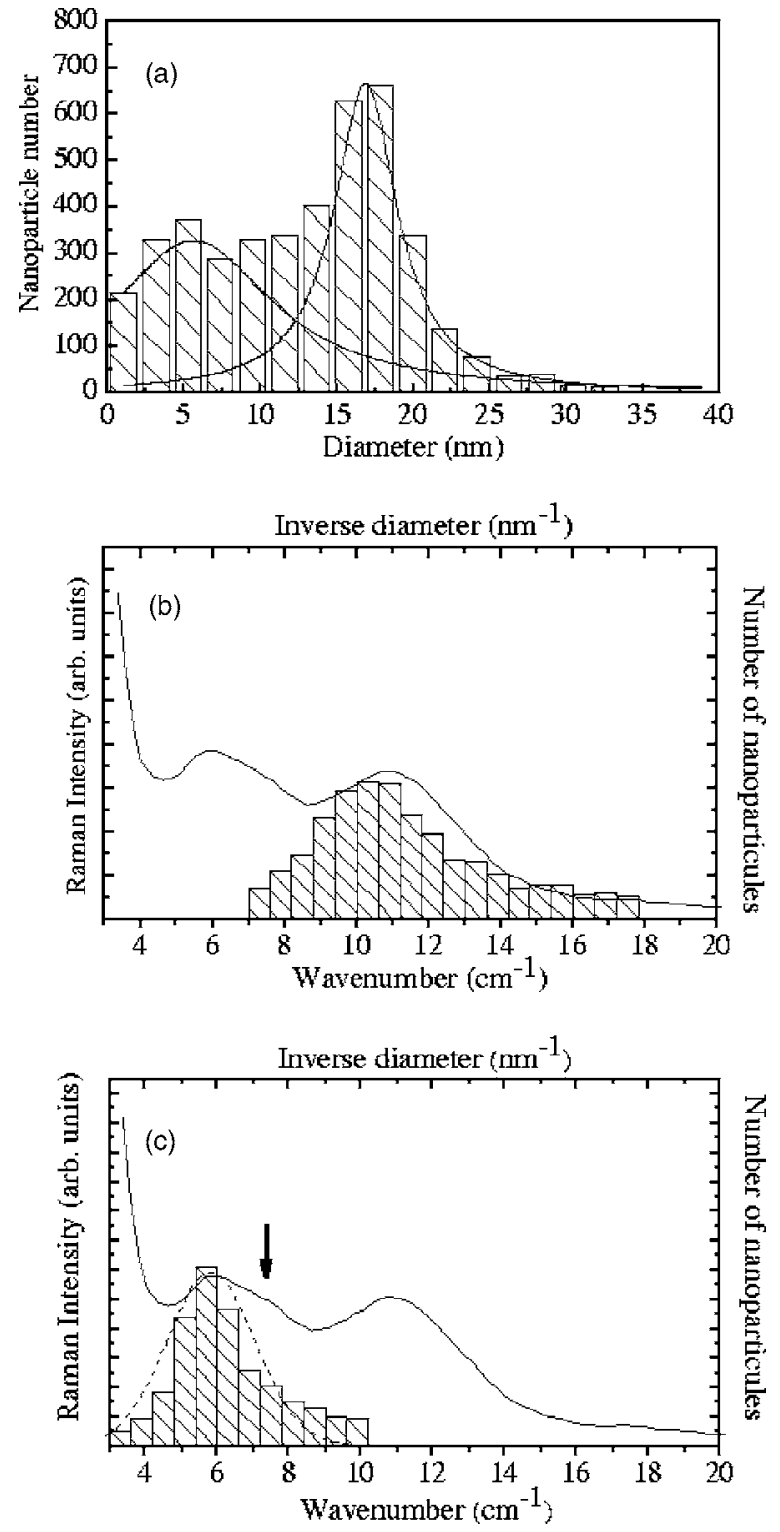

FIG. 4. (a) The diameter distribution of nanoparticles of sample $B$ (the full lines are the Lorentzian fits). Superpositions of the Stokes Raman spectrum [Fig. 3(a)] on the inverse diameter distribution for (b) $\mathrm{Ag}$ and (c) $\mathrm{Cu}-\mathrm{Ag}$ core-shell nanoparticles (the dashed line is a Gaussian fit on the maximum of the Raman peak).

the lattice fringes corresponds to pure $\mathrm{Ag}$ nanoparticles. $\mathrm{Ag}$ atoms cannot escape from local energy minima imposed by the available nucleation sites on the amorphous carbon film leading to the formation of small $\mathrm{Ag}$ nanoparticles.

In order to interpret the origin of the higher Raman peak of Fig. 3, the frequencies of the quadrupolar modes have been calculated for both species. Equation (1) can be directly used to compute the vibration frequencies of pure Ag particles. The deduced Ag particle diameter for an excitation at $2.7 \mathrm{eV}$ is reported in Table I in agreement with the mean diameter measured by TEM. The quadrupolar modes of $\mathrm{Cu}-\mathrm{Ag}$ core-shell nanoparticles can be calculated with the Lamb's approach including the Navier equation. ${ }^{16}$ We assume the displacement and the stress continuities at the coreshell interface and internal total reflection of the acoustic 
waves at the shell-air interface. ${ }^{17}$ Further, we used the mean diameter deduced from $\mathrm{Cu}$ nanoparticles of sample $A$ as the core diameter to calculate the Ag shell thickness (Table I). The calculated quadrupolar mode frequencies for the different excitation energies show that the frequency shift observed for the $\mathrm{Cu}-\mathrm{Ag}$ core-shell is mainly due to the ellipsoidal shape of the $\mathrm{Cu}$ core whereas the small shift measured for the Ag nanoparticles shows the spherical shape of these particles. In a previous Raman study of Ni-Ag core-shell nanoparticles, only the Ag shell vibration has been observed, leading to the conclusion of a weak bonding between $\mathrm{Ag}$ and $\mathrm{Ni}$ atoms. ${ }^{16}$ The presence of a Raman peak associated with the $\mathrm{Cu}-\mathrm{Ag}$ core-shell particles in our spectra indicates that there is a good phase matching of the acoustic wave between the shell and the core. Thus the bonding seems to be stronger between $\mathrm{Ag}$ and $\mathrm{Cu}$ than between $\mathrm{Ag}$ and $\mathrm{Ni}$.

The diameter distribution measured using high contrast HAADF images [Fig. 1(b)] contains two components related to $\mathrm{Cu}-\mathrm{Ag}$ core shell and $\mathrm{Ag}$ nanoparticles [Fig. 4(a)]. The reduction of the Raman probe to a $\mu$ scale allows a comparison of the Raman spectra with the size distributions of nanoparticles measured on the same area. It has already been found that the Raman intensity peak of nanoparticles is proportional to the inverse size distribution. ${ }^{9,18}$ Figures 4(b) and 4(c) exhibit the inverse diameter deduced from TEM superimposed to the Raman spectrum of sample $B$ measured at $2.7 \mathrm{eV}$. The Raman intensity of $\mathrm{Ag}$ nanoparticle peak matches the inverse diameter distribution [Fig. 4(b)] well. In Fig. 4(c), one can notice a discrepancy between Raman and TEM measurements on $\mathrm{Cu}-\mathrm{Ag}$ core-shell nanoparticles. The Rayleigh scattering prevents us to compare Raman and TEM distribution at low frequencies. Nevertheless, a Gaussian fit to the Raman peak shows a difference at higher wave numbers (around 7-8 $\mathrm{cm}^{-1}$ ) due to a slower decrease of the Raman intensity [which can be seen more clearly in the spectrum Fig. 3(c)] compared to the TEM nanoparticle size distribution. First, the discrepancy is located at the same wave number as the $\mathrm{Cu}$ nanoparticle peak of Fig. 2. The additional Raman contribution can originate from $\mathrm{Cu}-\mathrm{Ag}$ nanoparticles with a weak bonding between $\mathrm{Cu}$ and $\mathrm{Ag}$ leading to a Raman signal from the free $\mathrm{Cu}$ core and $\mathrm{Ag}$ shell. The latter is hidden in the high wave-number signal. This interpretation is also suggested by nanobeam diffraction on individual $\mathrm{Cu}-\mathrm{Ag}$ nanoparticles. Few particles present only one crystallographic axis oriented along the same direction for $\mathrm{Cu}$ and $\mathrm{Ag}$ reducing the sound phase matching between $\mathrm{Ag}$ and $\mathrm{Cu}$ atoms. ${ }^{19}$

The reduction of the Raman probe to $\mu$ scale has enabled direct comparison of the nanoparticle sizes, forms, and compositions to those obtained from TEM on the same area. Two different nanoparticle species have been detected with Raman and TEM probes: $\mathrm{Cu}-\mathrm{Ag}$ core-shell and pure Ag. For $\mathrm{Cu}-\mathrm{Ag}$ core-shell particles, two components in the Raman spectra can be distinguished depending on the sound phase matching between $\mathrm{Cu}$ core and $\mathrm{Ag}$ shell. It can be originated from the different orientations of the crystallographic axis between both materials. The direct correlation between Raman and TEM reveals the key role played by acoustic phonon properties at the scale of few particles that can aid to further understand the SERS effect.

The authors thank B. Capelle and E. Larquet for giving access to the TEM of the IMPMC (Paris) and Sawako Nakamae for a critical reading of the manuscript.

\footnotetext{
*Electronic address: maximilien.cazayous@espci.fr

${ }^{1}$ M. Moskovits, Rev. Mod. Phys. 57, 783 (1985).

${ }^{2}$ J. I. Gersten and A. Nitzan, Surf. Sci. 158, 165 (1985).

${ }^{3}$ D. A. Weitz, T. J. Gramila, A. Z. Genack, and J. I. Gersten, Phys. Rev. Lett. 45, 355 (1980).

${ }^{4}$ E. Duval, A. Boukenter, and B. Champagnon, Phys. Rev. Lett. 56, 2052 (1986).

${ }^{5}$ M. Fujii, T. Nagareda, S. Hayashi, and K. Yamamoto, Phys. Rev. B 44, 6243 (1991).

${ }^{6}$ B. Palpant, H. Portales, L. Saviot, J. Lermé, B. Prével, M. Pellarin, E. Duval, A. Perez, and M. Broyer, Phys. Rev. B 60, 17107 (1999).

${ }^{7}$ H. Portales, L. Saviot, E. Duval, M. Fujii, S. Hayashi, N. Del Fatti, and F. Valle, J. Chem. Phys. 115, 3444 (2001).

${ }^{8}$ E. Duval, A. Mermet, A. Courty, P. A. Albouy, and M. P. Pileni, Phys. Rev. B 72, 085439 (2005).

${ }^{9}$ A. Courty, A. Mermet, P. A. Albouy, E. Duval, and M. P. Pileni, Nat. Mater. 4, 395 (2005).

${ }^{10}$ W. Grogger, M. Varela, R. Ristau, B. Shaffer, F. Hofer, and K. M.
}

Krishnan, J. Electron Microsc. 143, 139 (2005).

${ }^{11}$ C. Ricolleau, L. Audinet, M. Gandais, and T. Gacoin, Thin Solid Films 336, 213 (1998).

${ }^{12}$ G. Bachelier and A. Mlayah, Phys. Rev. B 69, 205408 (2004).

${ }^{13}$ L. Saviot and D. B. Murray, Phys. Rev. B 72, 205433 (2005).

${ }^{14}$ H. Lamb, Proc. London Math. Soc. 13, 187 (1882).

${ }^{15}$ The used sound velocities are $v_{l}[\mathrm{Cu}]=4760 \mathrm{~m} / \mathrm{s}, \quad v_{l}[\mathrm{Ag}]$ $=3650 \mathrm{~m} / \mathrm{s}, v_{t}[\mathrm{Cu}]=2300 \mathrm{~m} / \mathrm{s}$ and $v_{t}[\mathrm{Ag}]=1660 \mathrm{~m} / \mathrm{s}$. The $\tau$ values for $\mathrm{Ag}$ and $\mathrm{Cu}$ nanoparticles are $2.89 \times 10^{-2}$ and 2.82 $\times 10^{-2} \mathrm{~m}^{-1} \mathrm{~s}$, respectively.

${ }^{16}$ H. Portales, L. Saviot, E. Duval, M. Gaudry, E. Cottancin, M. Pellarin, J. Lermé, and M. Broyer, Phys. Rev. B 65, 165422 (2002).

${ }^{17} \mathrm{The} \mathrm{Ag}$ and $\mathrm{Cu}$ density used in the calculation of the continuity conditions are, respectively, 10.63 and $8.93 \mathrm{~g} \mathrm{~cm}^{-3}$.

${ }^{18}$ E. Duval, H. Portales, L. Saviot, M. Fujii, K. Sumitomo, and S. Hayashi, Phys. Rev. B 63, 075405 (2001).

${ }^{19}$ C. Langlois, T. Oikawa, C. Ricolleau, M. Cazayous, and A. Sacuto (unpublished). 